\title{
HAZARD ANALYSIS AND CRITICAL CONTROL POINT (HACCP)
}

\author{
T. Stamov* \\ Trakia University, Stara Zagora, Bulgaria
}

\begin{abstract}
The HACCP system, which is science based and systematic, identifies specific hazards and measures for their control to ensure the safety of food. HACCP is a tool to assess hazards and establish control systems that focus on prevention rather than relying mainly on end-product testing. Any HACCP system is capable of accommodating change, such as advances in equipment design, processing procedures or technological developments.HACCP can be applied throughout the food chain from primary production to final consumption and its implementation should be guided by scientific evidence of risks to human health. As well as enhancing food safety, implementation of HACCP can provide other significant benefits. In addition, the application of HACCP systems can aid inspection by regulatory authorities and promote international trade by increasing confidence in food safety. (1)
\end{abstract}

Key words: points, hazard, HACCP, critical, food, control, system, principle, establish

The HACCP system consists of the following seven principles(1):

- PRINCIPLE 1-Conduct a hazard analysis.

- PRINCIPLE 2-Determine the Critical Control Points (CCPs).

- PRINCIPLE 3-Establish critical limit(s).

- PRINCIPLE 4-Establish a system to monitor control of the CCP.

- PRINCIPLE 5-Establish the corrective action to be taken when monitoring indicates that a particular CCP is not under control.

- PRINCIPLE 6-Establish procedures for verification to confirm that the HACCP system is working effectively.

- PRINCIPLE 7-Establish documentation concerning all procedures and records appropriate to these principles and their application

\section{PRINCIPLES OF THE HACCP SYSTEM \\ Principle 1 - Conduct a Hazard Analysis}

The application of this principle involves listing the steps in the process and identifying where significant hazards are likely to Occur. The HACCP team will focus on hazards that can be prevented, eliminated or controlled by the HACCP plan. (2)

\footnotetext{
*Correspondence to: student Teodor Stamov; Trakia University, Faculty of Economics, Stara Zagora, Bulgaria; e-mail: teodor.stamov@abv.bg; www.uni-sz.bg
}

\section{Principle 2 - Identify the Critical Control Points}

A critical control point (CCP) is a point, step or procedure at which control can be applied and a food safety hazard can be prevented, eliminated or reduced to acceptable levels. The HACCP team will use a CCP decision tree to help identify the critical control points in the process. A critical control point may control more that one food safety hazard or in some cases more than one CCP is needed to control a single hazard. (2)

\section{Principle 3 - Establish Critical Limits}

A critical limit (CL) is the maximum and/or minimum value to which a biological, chemical, or physical parameter must be controlled at a CCP to prevent, eliminate, or reduce to an acceptable level the occurrence of a food safety hazard. The critical limit is usually a measure such as time, temperature, water activity (Aw), $\mathrm{pH}$, weight, or some other measure that is based on scientific literature and/or regulatory standards. (2)

\section{Principle 4- Monitor CCP}

The HACCP team will describe monitoring procedures for the measurement of the critical limit at each critical control point. Monitoring procedures should describe how the measurement will be taken, when the measurement is taken, who is responsible for 
the measurement and how frequently the measurement is taken during production. (2)

\section{Principle 5 - Establish Corrective Action}

Corrective actions are the procedures that are followed when a deviation in a critical limit occurs. The HACCP team will identify the steps that will be taken to prevent potentially hazardous food from entering the food chain and the steps that are needed to correct the process. This usually includes identification of the problems and the steps taken to assure that the problem will not occur again. (2)

\section{Principle 6 - Verification}

Those activities, other than monitoring, that determine the validity of the HACCP plan and that the system is operating according to the plan. The HACCP team may identify activities such as auditing of CCP's, record review, prior shipment review, instrument calibration and product testing as part of the verification activities. (2)

\section{Principle 7 - Recordkeeping}

A key component of the HACCP plan is recording information that can be used to prove that the a food was produced safely. The records also need to include information about the HACCP plan. Record should include information on the HACCP Team, product description, flow diagrams, the hazard analysis, the CCP's identified, Critical Limits, Monitoring System, Corrective Actions, Recordkeeping Procedures, and Verification Procedures. (2)

\section{APPLICATION}

The application of HACCP principles consists of the following tasks as identified in the Logic Sequence for Application of HACCP (Diagram 2).

\section{Assemble HACCP team}

The food operation should assure that the appropriate product specific knowledge and expertise is available for the development of an effective HACCP plan. Optimally, this may be accomplished by assembling a multidisciplinary team. Where such expertise is not available on site, expert advice should be obtained from other sources. The scope of the HACCP plan should be identified. The scope should describe which segment of the food chain is involved and the general classes of hazards to be addressed (e.g. does it cover all classes of hazards or only selected classes). (1)

\section{Describe product}

STAMOVT.

A full description of the product should be drawn up, including relevant safety information such as: composition, physical/chemical structure (including $\mathrm{A}_{\mathrm{w}}, \mathrm{pH}$, etc.), microcidal/static treatments (heattreatment, freezing, brining, smoking, etc.), packaging, durability and storage conditions and method of distribution. (1)

\section{Identify intended use}

The intended use should be based on the expected uses of the product by the end user or consumer. In specific cases, vulnerable groups of the population, e.g. institutional feeding, may have to be considered. (1)

\section{Construct flow diagram}

The flow diagram should be constructed by the HACCP team. The flow diagram should cover all steps in the operation. When applying HACCP to a given operation, consideration should be given to steps preceding and following the specified operation. (1)

\section{On-site confirmation of flow diagram}

The HACCP team should confirm the processing operation against the flow diagram during all stages and hours of operation and amend the flow diagram where appropriate. (1)

\section{List all potential hazards associated with each step, conduct a hazard analysis, and consider any measures to control identified hazards \\ (SEE PRINCIPLE 1)}

The HACCP team should list all of the hazards that may be reasonably expected to occur at each step from primary production, processing, manufacture, and distribution until the point of consumption. The HACCP team should next conduct a hazard analysis to identify for the HACCP plan which hazards are of such a nature that their elimination or reduction to acceptable levels is essential to the production of a safe food. (1)

In conducting the hazard analysis, wherever possible the following should be included:

- the likely occurrence of hazards and severity of their adverse health effects;

- the qualitative and/or quantitative evaluation of the presence of hazards;

- survival or multiplication of microorganisms of concern;

- production or persistence in foods of toxins, chemicals or physical agents; and,

- conditions leading to the above. 


\section{Determine Critical Control Points (SEE PRINCIPLE 2)}

There may be more than one CCP at which control is applied to address the same hazard. The determination of a CCP in the HACCP system can be facilitated by the application of a decision tree (e.g. Diagram 2), which indicates a logic reasoning approach. Application of a decision tree should be flexible, given whether the operation is for production, slaughter, processing, storage, distribution or other. It should be used for guidance when determining CCPs. This example of a decision tree may not be applicable to all situations. Other approaches may be used. Training in the application of the decision tree is recommended. If a hazard has been identified at a step where control is necessary for safety, and no control measure exists at that step, or any other, then the product or process should be modified at that step, or at any earlier or later stage, to include a control measure. (1)

\section{Establish critical limits for each CCP (SEE PRINCIPLE 3)}

Critical limits must be specified and validated if possible for each Critical Control Point. In some cases more than one critical limit will be elaborated at a particular step. Criteria often used include measurements of temperature, time, moisture level, $\mathrm{pH}, \mathrm{A}_{\mathrm{w}}$, available chlorine, and sensory parameters such as visual appearance and texture. (1)

\section{Establish a monitoring system for each CCP (SEE PRINCIPLE 4)}

Monitoring is the scheduled measurement or observation of a CCP relative to its critical limits. The monitoring procedures must be able to detect loss of control at the CCP. Further, monitoring should ideally provide this information in time to make adjustments to ensure control of the process to prevent violating the critical limits. Where possible, process adjustments should be made when monitoring results indicate a trend towards loss of control at a CCP. The adjustments should be taken before a deviation occurs. Data derived from monitoring must be evaluated by a designated person with knowledge and authority to carry out corrective actions when indicated. If monitoring is not continuous, then the amount or frequency of monitoring must be sufficient to guarantee the CCP is in control. Most monitoring procedures for CCPs will need to be done rapidly because they relate to on-line processes and there will not be time for lengthy analytical testing. Physical and chemical measurements are often preferred to microbiological testing because they may be
STAMOVT.

done rapidly and can often indicate the microbiological control of the product. All records and documents associated with monitoring CCPs must be signed by the person(s) doing the monitoring and by a responsible reviewing official(s) of the company. (1)

\section{Establish corrective actions (SEE PRINCIPLE 5)}

Specific corrective actions must be developed for each CCP in the HACCP system in order to deal with deviations when they occur.The actions must ensure that the CCP has been brought under control. Actions taken must also include proper disposition of the affected product. Deviation and product disposition procedures must be documented in the HACCP record keeping. (1)

\section{Establish verification procedures (SEE PRINCIPLE 6)}

Establish procedures for verification. Verification and auditing methods, procedures and tests, including random sampling and analysis, can be used to determine if the HACCP system is working correctly. The frequency of verification should be sufficient to confirm that the HACCP system is working effectively. Examples of verification activities include:

- Review of the HACCP system and its records;

- Review of deviations and product dispositions;

- Confirmation that CCPs are kept under control.

Where possible, validation activities should include actions to confirm the efficacy of all elements of the HACCP plan. (1)

\section{Establish Documentation and Record Keeping (SEE PRINCIPLE 7)}

Efficient and accurate record keeping is essential to the application of a HACCP system. HACCP procedures should be documented. Documentation and record keeping should be appropriate to the nature and size of the operation. (1)

Documentation examples are:

- Hazard analysis;

- CCP determination;

- Critical limit determination.

\section{REFERENCES}
1. FOOD
AND
AGRICULTURE ORGANIZATION OF THE UNITED NATIONS
http://www.fao.org/3/Y1579E/y1579e03.htm
2. Institute of Agriculture and Natural Resources https://food.unl.edu/seven-principles-haccp 